\title{
Influência da Mudança de Gestão nas Estratégias de uma Cooperativa Agropecuária
}

\author{
Luiz Marcelo Antonialli
}

\section{ResUMO}

O presente trabalho teve por objetivo analisar a influência da mudança de gestão nas estratégias de uma cooperativa agropecuária do sul de Minas Gerais. Os resultados demonstraram que os entrevistados têm consciência das forças ambientais, às quais a cooperativa está exposta, porém concordam em que a resposta da organização ao ambiente tem sido lenta, principalmente porque as decisões estratégicas são tomadas de forma colegiada, em esporádicas assembléias que, no geral, apresentam baixa participação dos associados. Não há planejamento estratégico na cooperativa. As estratégias limitam-se às propostas divulgadas pelas chapas na época da eleição, as quais tendem a constituir o compromisso do mandato. Tal fato pode influenciar as estratégias, tanto em nível de formulação quanto de implementação, e provocar sua descontinuidade no longo prazo. Os principais fatores que podem influenciar as estratégias da cooperativa devido à mudança de gestão são: ausência de planejamento estratégico, amadorismo gerencial da diretoria e divergências políticas dos grupos de interesse envolvidos na disputa do poder. A última eleição de diretoria na cooperativa caracterizou-se como incidente crítico para a organização, afetou o clima organizacional com reflexos traumáticos para todos os envolvidos no processo: membros da chapa vencedora e perdedora, funcionários e cooperados.

Palavras-chaves: mudança de gestão; eleição da diretoria; estratégia; cooperativa; agropecuária.

\begin{abstract}
The present work aimed to analyse the influence of the shift of administration on the strategies of an agricultural cooperative in southern Minas Gerais, Brazil. The results showed the interviewees are aware of the environmental forces to which the cooperative is exposed but they agree that the response of the organization to environment has infrequent gatherings which in general present poor participation of the members. There are no strategical planning in the cooperative. The strategies limit themselves to the proposals divulged by the slates at the time of election, which during the mandate are seeked to fulfill. Such a fact may influence the strategies, both at the formulation and implementation level and cause its discontinuation at long term. The chief factors which may influence the strategies of the cooperative due to the shift of administration are: absence of strategical planning, managerial amateurism of the board of directors and political divergence of the concerned groups involved in power disputes. The last election for the board of directors in the studied cooperative was characterized as a critical incident for the organization, having affected the organizational climate with traumatic reflexes to all involved in the process: members in the winning and defeated slate, employees and members.
\end{abstract}

Key words: administration shift; election of the board of directors; strategy; cooperative; farming. 


\section{INTRODUÇĀO}

Para discutir a real importância das organizações cooperativas deve-se tomar por base seus princípios doutrinários e associativos. Essencialmente, a cooperativa é uma associação de pessoas, em bases democráticas, que se unem com o objetivo de atender a certas necessidades econômicas fundamentais, manifestando duas dimensões básicas: de instituição política, interessada na organização e promoção social de seus membros e, ao mesmo tempo, um empreendimento econômico que se obriga a produzir algum bem ou serviço dentro de um grau relativo de eficiência econômica. A propriedade de articular, dentro de uma mesma organização, essas duas dimensões (a política e a econômica) confere às cooperativas seu caráter específico.

Enquanto diretriz doutrinária, as cooperativas se propõem a ser uma solução simples e prática para conflitos existentes entre as mencionadas características: a do cidadão, que enfatiza o bem público e a responsabilidade social, e a do ator econômico, interessado na produção eficiente de bens ou serviços (Garcia, 1981). Dessa forma, as cooperativas assumem, devido aos seus princípios doutrinários, a dupla função de associação, enquanto reunião de pessoas, e de empresa, enquanto reunião de capital. Por outro lado, os cooperados também assumem o duplo papel de dono e, ao mesmo tempo, de usuário do empreendimento. Diante dessas características peculiares das cooperativas, na maioria delas ocorre o processo de autogestão, pois são geridas pelos próprios donos/usuários.

Advoga Schulze (1987) que o associado, como gestor do empreendimento comum, deve harmonizar a sua participação política, na definição de objetivos e metas, com a sua participação econômica, isto é, no capital e operações, e ambas com a capacidade gerencial da empresa em efetivar suas relações com o mercado. Dessa forma, a cooperativa, como amplo espaço em que interage grande número de associados, resulta em evidente espaço de disputa de poder. Nele, diferentes forças atuantes precisam ser coordenadas e disciplinadas no sentido de orientá-las para o cumprimento do objetivo da cooperativa de prestar serviços aos associados.

O processo de globalização da economia, as mudanças no cenário econômico nacional e o inevitável aumento da competitividade global vêm exigindo das cooperativas brasileiras uma revisão de seus princípios e doutrinas, como forma de se adaptarem a esses novos tempos. Rever seus produtos, suas estratégias e estruturas administrativas são ações que visam a aumentar a eficácia e a competitividade dessas organizações (Gramacho, 1997; Rodrigues, 1997). 
Pereira e Brito (1994), ao estudarem as relações de poder em uma cooperativa agrícola, detectaram a dimensão política e os conflitos de interesses na organização. Ao assistirem a uma assembléia geral, verificaram os jogos dos grupos de interesse ao participarem de um processo decisório, que revelaram o uso de táticas e contratáticas no exercício do poder.

Para disciplinar e regulamentar os conflitos e interesses nas cooperativas brasileiras, a estrutura formal de poder é regulamentada por uma legislação específica do Governo Federal, sendo o processo particularizado em cada cooperativa mediante estatuto próprio.

O problema central da pesquisa fundamenta-se no fato de que a mudança de poder pode provocar descontinuidade nas estratégias da cooperativa por dificultar a sua elaboração e implementação a médio e longo prazo. Essa provável descontinuidade nas estratégias pode provocar mudanças nos rumos da organização com risco de perder competitividade no mercado.

O objetivo central deste trabalho foi analisar as influências da mudança de gestão nas estratégias de uma cooperativa agropecuária, localizada no sul de Minas Gerais. Especificamente, buscou-se:

- analisar o ambiente externo (oportunidades e ameaças) ao qual a cooperativa está exposta, bem como o ambiente interno (pontos fortes e fracos) da organização;

- analisar o último processo eleitoral na cooperativa, procurando compreender as articulações políticas das chapas envolvidas no processo;

investigar, sob diversas perspectivas, os membros da chapa vencedora, os membros da chapa perdedora, os funcionários de médio escalão e líderes de cooperados para saber quais seriam os principais fatores, envolvidos na mudança de gestão, que poderiam influenciar as estratégias da cooperativa.

\section{FundamentaÇÃo TEÓRICA}

\section{Cultura Organizacional e o Cooperativismo}

A cultura organizacional é definida por Schein $(1985$, p. 6) como o "conjunto de pressupostos básicos que um grupo inventou, descobriu ou desenvolveu, ao aprender como lidar com os problemas de adaptação externa e integração interna e que funcionam bem o suficiente para serem considerados válidos e ensinados a novos membros como forma correta de perceber, pensar e sentir, em relação a 
esses problemas". Segundo o autor, a cultura organizacional divide-se em três níveis: pressupostos básicos, valores e ideologia, e artefatos visíveis. Entre os pressupostos básicos, ressalta-se a orientação relativa ao tempo e ao seu uso, a relação do homem com a natureza, os conceitos de espaço e o relacionamento dos homens entre si. Entre os valores e a ideologia, incluem-se os ideais e as normas de comportamento; entre os artefatos visíveis incluem-se a linguagem, a tecnologia e a organização social.

Incorporando a dimensão política inerente ao fenômeno cultural nas organizações, Fischer (1989) cita Fleury; esta afirma que essa dimensão é concebida como conjunto de valores e pressupostos básicos expressos em elementos simbólicos que, em sua capacidade de ordenar, atribuir significações e construir a identidade organizacional, tanto agem como elemento de comunicação e consenso, como ocultam e instrumentalizam as relações de dominação.

A doutrina cooperativista surgiu em 1844, na Inglaterra, por meio do movimento de um grupo tecelões que fundou uma cooperativa de consumo denominada Rochdale Society of Equitable Pioners, cujo objetivo era encontrar formas para melhorar sua situação econômica. Este fato simbolizou o início do movimento cooperativista que se alastrou por todo o mundo (Pinho, 1966; Maurer Júnior, 1970; César, 1977; Pinho, 1981; Oliveira, 1984; Silva, 1994).

No cenário mundial, o órgão representativo do movimento cooperativista é a Aliança Cooperativa Internacional (ACI ), com sede em Genebra, Suíça, fundada em 1895 e classificada por Chomel (1992) como uma organização não governamental (ONG) internacional. Congrega, em 82 países, 203 organizações e 662.970.545 pessoas (ACI, 1992).

Segundo vários autores (Pinho, 1966; César, 1977; Pinho, 1981; Oliveira, 1984; Silva, 1994; Bernardo, 1996), o cooperativismo moderno é explicado e fundamentado com base nos chamados Princípios dos Pioneiros de Rochdale. A legislação brasileira (Lei 5.764/1971), rochdaleana em sua base, legitima os princípios que foram acolhidos pela ACI, quais sejam: adesão livre, controle democrático, retorno pro-rata das operações, juros limitados ao capital, desenvolvimento da educação e a intercooperação.

Por apresentarem, em sua essência, ideais socialistas, alguns desses princípios vêm sendo modificados ou abandonados ao longo do tempo, diante da necessidade de adaptação às transformações capitalistas.

Existem princípios polêmicos, como o controle democrático e adesão livre, que vêm sofrendo severas críticas para que sejam reformulados na tentativa de imprimir a racionalidade econômica e administrativa nas cooperativas, buscando eficá- 
cia interna e externa para alcançarem maior competitividade em relação às empresas não-cooperativas (Zylbersztajn, 1994; Bernardo, 1996; Jank, 1997). No caso do controle democrático, as decisões tomadas na assembléia geral baseiamse no princípio segundo o qual cada cooperado tem direito a um voto, independentemente de sua participação no capital da cooperativa ou no seu movimento enquanto produtor. Esse preceito deixa com igual poder de influência nas decisões, tanto um cooperado altamente produtivo quanto aquele outro com eventual participação nos negócios.

Jank (1997) advoga que os problemas atuais do cooperativismo passam por soluções relativamente radicais, que podem ser definidas por sete itens:

. seleção de cooperados ativos, com base no grau de fidelidade, comprometimento e eficiência econômica;

. eliminação do critério de livre entrada na cooperativa, definindo padrões rígidos de participação no negócio;

- profissionalização da gerência, desenvolvendo sistemas modernos de controle e avaliação, incluindo os conselhos de administração e fiscal;

- desenvolver novos critérios de pagamento dos cooperados ou valorizar o indivíduo que traz benefícios em termos de volume, qualidade e redução da sazonalidade de oferta, por exemplo, no caso do leite;

- discutir novos critérios de votação em assembléia, que favoreçam a continuidade do desempenho econômico e, em caso de sucessão, a harmonia das boas diretrizes;

- encontrar formas de acesso a capital de risco para novos investimentos; tornar mais ágeis as decisões de mercado e, neste ponto, é muito oportuna a discussão sobre a criação de subsidiárias na forma de sociedades anônimas;

. entender e gerenciar o processo de adição de valor; hoje é possível verticalizar a produção, sem necessariamente construir fábricas, por meio da coordenação com outras empresas via joint ventures e outras alianças estratégicas.

Neste sentido, a separação entre a propriedade e o controle na gestão de cooperativas é tema muito discutido na atualidade. Tal discussão tem fundamento, quando o crescimento das estruturas cooperativas é seguido de aumento da complexidade de sua gestão, ao mesmo tempo que as cooperativas demandam gerentes qualificados para tratar dos complexos problemas do agribusiness. Entretanto ainda existe forte propensão a manter o corpo gerencial formado por cooperados (Zylbersztajn, 1994; Silva, 1994). 
As mudanças na doutrina cooperativista, necessárias para aumentar a competitividade dessas organizações no mercado, enfrentam resistências, tanto em relação aos indivíduos como coletivamente. Para Ansoff (1990), no caso dos indivíduos, as resistências à mudança estão associadas à insegurança e/ou ameaça da perda de poder, enquanto no coletivo as causas são de natureza cultural e política.

\section{Estrutura de Poder nas Cooperativas}

O poder é definido por Galbraith (1989) como a capacidade de impor a vontade e atingir o correspondente objetivo. Foucault (1993) acrescenta que o poder é algo que circula, ou melhor, é algo que só funciona em cadeia, que funciona e se exerce em rede. No mesmo sentido, Fischer (1989) ressalta que o poder está embutido nos padrões culturais vigentes, está presente em todas as esferas da instituição, atinge diferentes agentes organizacionais e é por eles manipulado nas disputas de interesses e influências.

Segundo Zalesnik e Vries (1981), as práticas administrativas têm demonstrado que tais conflitos de interesses fazem com que a organização seja mais política do que ideológica; entretanto a emergência desses conflitos torna possível o processo de negociação, o qual envolve jogos de poder e estratégias de ação política. Morgan (1996) discute a idéia de que as organizações se comportam como sistemas políticos, em que claramente se manifestam as relações entre interesses, conflitos e poder. Algumas vezes, ocupam o centro das atenções, bem como nas incontáveis intrigas interpessoais provocam desvios no fluxo da atividade organizacional.

Para Pagès (1987), o poder organizacional não deve ser ingenuamente atribuído a determinadas pessoas ou grupos, tampouco localizado em algum ponto específico da estrutura organizacional. Por não constituir uma entidade que possa ser possuída, o poder difunde-se através do corpo da organização, manifestando-se por meio de práticas e relações, cuja eficácia se baseia na capacidade de ocultar as contradições existentes pelo exercício da mediação.

A origem da estrutura de poder nas cooperativas está associada ao processo de desenvolvimento tecnológico da agricultura brasileira, atendendo a interesses do Estado e seus aliados de imprimir um enfoque de expansão do capitalismo no campo em nome do aproveitamento das oportunidades do mercado e na busca da satisfação econômica dos associados. Muitos autores discutem que as cooperativas brasileiras serviram de suporte para expansão do capitalismo no campo, observando-se um enriquecimento das cooperativas numa proporção inversa ao de seus associados. Como conseqüência, verificou-se que o setor rural brasileiro passou, a partir da década de 50, por um processo de concentração de poder e de renda (Alencar, 1976; Sorj, 1980; Fleury, 1983; Bursztyn, 1985; Oliveira, 1996). 
Alencar (1976) constatou o distanciamento dos associados em relação à cooperativa, como conseqüência das práticas administrativas impostas pelo modelo de desenvolvimento capitalista que facilitou mais ainda a concentração de poder; conclui que, à medida que a cooperativa é considerada pelos produtores como agência instrumental para a satisfação de suas necessidades econômicas individuais e não como meio político-econômico, os princípios ideológicos do cooperativismo, ou doutrina cooperativista, adquirem pouco significado, como orientação do ator, no sentido de decidir pela permanência e lealdade à cooperativa.

Para reforçar, Meireles (1981) assevera que a participação da cooperativa em mercado competitivo capitalista tem levado à adoção de métodos racionais de administração, com conseqüente surgimento e desenvolvimento de um corpo técnico-burocrático específico.

Segundo Schulze (1987), o cooperativismo brasileiro, a partir de 1903, foi objeto de cerca de vinte títulos legais no âmbito federal, entre os específicos e correlatos. Entretanto a Lei 5.764/71 estabelece, até os dias atuais, a estrutura básica do poder formal nas cooperativas. De acordo com Oliveira (1984) e Schulze (1987), a Lei 5.764 de 16 de dezembro de 1971 que regulamenta o cooperativismo no país, identifica a Assembléia Geral como o órgão supremo da sociedade, podendo ser ordinária (AGO) ou extraordinária (AGE) e ainda os Órgãos de Administração e o Conselho Fiscal. Vale ressaltar que a lei estabelece as diretrizes gerais, sendo interpretada e regulamentada pelo Estatuto Social de cada cooperativa.

A legislação cooperativa no Brasil segue o modelo de administração que Carbonell de Masy (1980) define como modelo latino, ou seja, ao Conselho de Administração cabe a direção e administração da cooperativa, por ser órgão diretivo e executivo; o Conselho Fiscal é um órgão permanentemente encarregado de verificar o bom manejo econômico-financeiro da cooperativa e de zelar pelo cumprimento de toda as normas; a gerência, sob a supervisão do Conselho de Administração, tem a seu cargo o manejo dos negócios ordinários e normais das cooperativas.

Quanto à questão eleitoral, Schulze (1987) comenta que, havendo ou não inscrição prévia de candidatos e seja esta através de chapa ou pela manifestação individual do candidato, realizando-se a eleição no transcurso da Assembléia Geral, o confronto de grupos oponentes será sempre traumático para a cooperativa. As eleições, em geral, estão definidas no ato da instalação da assembléia, ganhandoas aquele que convencer maior número de associados.

Discutindo, em essência, o modelo de administração proposto pela legislação cooperativista brasileira, Lauschner e Schweinberger (1989) afirmam que o mo- 
delo permite que as pessoas merecedoras de confiança dos associados, que não são necessariamente as mais capacitadas para dirigir e administrar uma cooperativa ou para controlá-la adequadamente, assumam o poder.

A atual estrutura de poder nas cooperativas brasileiras vem recebendo muitas críticas (Carbonell de Masy, 1978; Cário, 1985; Schulze, 1987; Lauschner e Schweinberger, 1989; Silva, 1994; Bernardo, 1996; Jank, 1997; Balde Branco, 1997), pois apresenta várias deficiências que vêm comprometendo a competitividade dessas organizações em relação às organizações não cooperativas, principalmente devido à ineficácia administrativa apresentada. Entre os problemas citados, pode-se listar a lentidão nas decisões por envolver consenso entre os cooperados, falta de competência administrativa dos dirigentes, centralização do poder, rodízio do poder entre um grupo de associados, remuneração demasiada dos dirigentes, motivando-os a serem assalariados ao invés de produtores, pouca participação dos associados nas assembléias, falta de planejamento de longo prazo, entre outros.

Fleury (1983), analisando as cooperativas de laticínios do Estado de São Paulo e suas relações com os produtores, conclui que são significativas as diferenças entre a cooperativa e a empresa privada, em termos de objetivos e modelo organizacional. Na cooperativa, organizada segundo o modelo democrático, observouse serem propícias as condições para que certos grupos se apropriem do poder e o utilizem em benefício próprio. Estes grupos, formados pelos grandes produtores, notadamente capitalistas, são os que realmente participam da vida política da cooperativa, revertendo esta participação em vantagens econômicas. Na empresa privada atuando no mesmo setor, o objetivo do lucro leva-a a se estruturar segundo o modelo de racionalidade técnica, sobre o qual não têm voz ativa os acionistas e sim os técnicos especialistas, modelo que procura propiciar as condições necessárias para realização do objetivo proposto.

Na opinião de Moraes (1994), o cooperativismo deveria encaminhar seus esforços no sentido da promoção de uma sociedade de maior participação decisória e de maior igualdade econômica e social, contribuindo para superar as causas estruturais e de outra ordem que levam à formação de classes sociais antagônicas: umas privilegiadas e outras marginalizadas em termos de poder, apropriação e usufruto das riquezas, do emprego, da tecnologia e da cultura.

\section{Estratégia Empresarial}

Recentemente, a preocupação com o conceito de estratégia e de administração estratégica tem levado as empresas à retomada de perguntas essenciais sobre a missão e os objetivos empresariais: que somos?, que queremos ser? e mais ain- 
da, fundamentalmente, a pergunta sobre como passar do que somos para o que queremos ser?.

A decisão é um problema geral das atividades da empresa que consiste em configurar e dirigir o processo de conversão de recursos de maneira a otimizar a consecução dos objetivos. Neste processo, caracterizam-se três níveis de decisões: estratégicas, administrativas e operacionais, que são interdependentes e complementares (Ansoff, 1977).

As decisões estratégicas, segundo Fischmann e Almeida (1991), dizem respeito ao caminho que a organização como um todo deverá seguir, e só recentemente têm merecido maior atenção dos administradores, que procuram desenvolver técnicas para facilitar o trabalho de conduzir a organização na melhor direção.

O planejamento estratégico caracteriza-se por ser um processo de longo prazo, que lida com decisões de efeitos duradouros e difíceis de serem modificadas. As decisões estratégicas são aquelas que mais afetam as atividades da organização, pois dizem respeito tanto à formulação de objetivos quanto à escolha dos meios para atingi-los; o planejamento estratégico se orienta, portanto, para os meios e para os fins (Ackoff, 1976; Oliveira, 1989).

Fischmann e Almeida (1991) definem o planejamento estratégico como técnica administrativa que, por meio da análise do ambiente de uma organização, cria a consciência das suas oportunidades e ameaças dos seus pontos fortes e fracos para o cumprimento da sua missão e, mediante esta consciência, estabelece o propósito de direção que a organização deverá seguir para aproveitar as oportunidades e evitar os riscos. Já o planejamento tático (orçamento) é um planejamento de curto prazo, predominantemente quantitativo, que abrange decisões administrativas e operações e visa à eficiência da organização.

A divisão das atividades do planejamento estratégico e sua implementação em etapas têm sua importância didática para o entendimento do processo e para facilitar a realização e o acompanhamento do cronograma; a seqüência de etapas não é algo rígido, variando tanto entre autores como entre organizações. Embora o planejamento estratégico seja feito com horizonte longo de tempo, ele deve ser refeito todos os anos para incluir as alterações que acontecerem no ambiente (Fischmann e Almeida, 1991).

A implementação, para Fischmann (1987), é inerente à administração, constituindo-se na etapa em que se dá, ou não, a conversão do planejado em realidade. Como tal, apresenta-se usualmente como um momento de tensão, porque, em geral, nossas aspirações suplantam nossas capacidades e disponibilidades de recursos; essa tensão torna-se maior sempre que as aspirações, traduzidas em pla- 
nos, se voltam para a introdução de inovações que representam mudanças organizacionais relevantes.

A essência da formulação de uma estratégia competitiva consiste em relacionar a empresa com seu meio ambiente. Isto significa visualizar a empresa inserta em um contexto geral no qual atua uma série de variáveis ligadas à competência, aos consumidores, ao contexto nacional e ao contexto mundial (Hermida, Serra e Kastika, 1992).

\section{Metodologia}

O presente estudo enquadra-se no método denominado estudo de caso e possui natureza de pesquisa qualitativa. São muitos os autores que ressaltam as características e importância desse tipo de pesquisa em administração, entre eles: Yin (1989), Fleury (1989), Triviños (1992) e Godoy (1995).

A fim de manter o sigilo, denominou-se a cooperativa estudada de Alfa, a qual se localiza na região sul de Minas Gerais, e mantém como principais atividades econômicas a produção de leite e café. Alfa possui 177 funcionários; seu quadro social é composto por 1110 cooperados, destacando-se os produtores de leite e café. Seu estatuto prevê eleições a cada 3 anos. A gestão anterior (formada por uma chapa de consenso) administrou a cooperativa entre abril de 1993 a março de 1996. A gestão eleita em março de1996 atuou de abril de 1996 a março de 1999.

Como instrumentos de coleta de dados utilizou-se a análise documental e a entrevista pessoal. $\mathrm{Na}$ análise documental utilizou-se o estatuto da cooperativa, relatórios anuais de gestão e jornais internos, a fim de recuperar dados históricos da organização.

Foram entrevistados, no total, 12 cooperados e 10 funcionários de médio escalão. $\mathrm{Na}$ entrevista seguiu-se um roteiro preestabelecido direcionado para cada grupo de indivíduos, cooperados e funcionários. Entre os cooperados, 4 integraram a chapa vencedora na última eleição focalizada, tornando-se membros da diretoria: diretor presidente, diretor financeiro, diretor administrativo e um membro do conselho de administração. Também foram entrevistados 4 cooperados integrantes da chapa perdedora. Os outros 4 cooperados entrevistados, considerados como líderes, não fizeram parte de nenhuma das duas chapas que disputaram a última eleição investigada. As entrevistas foram gravadas, com a permissão de 8 cooperados e apenas um funcionário. As respostas dos demais entrevistados foram anotadas. 
Devido à natureza qualitativa da pesquisa, utilizou-se a amostragem não-probabilística; nesse sentido, a justificativa para a escolha de cada grupo de indivíduos (membros das chapas vencedora e perdedora, funcionários de médio escalão e cooperados) seguiu critérios diferentes, com os apresentados em seguida:

. No caso das chapas vencedora e perdedora, cada uma composta por 12 indivíduos ( 3 membros da diretoria executiva, 3 membros do conselho de administração e 6 membros do conselho fiscal entre efetivos e suplentes), julgou-se que deveriam ser priorizados na escolha aqueles integrantes da diretoria executiva e conselho de administração por estarem envolvidos mais diretamente nas decisões do cotidiano administrativo da organização; nesse sentido, evitou-se a escolha de membros do conselho fiscal por exercerem a função restrita de fiscalização das ações da diretoria executiva.

. No caso dos funcionários, do total de 177 contratados procurou-se focalizar aqueles ligados mais diretamente às funções administrativas; entre eles, 48 foram considerados de médio escalão, por ocuparem cargos em setores administrativos e de supervisão de departamentos técnicos; entre eles, 10 foram entrevistados: contabilidade (2), contas a pagar (1), setor de pessoal (1), setor de compras (2), setor de processamento de dados (1), loja de insumos (1), laticínios (1), fábrica de ração (1).

- No caso dos cooperados, trata-se de categoria numerosa e a pesquisa apresentou limitações de tempo e recursos; assim, adotou-se como tática escolher aqueles considerados líderes, formadores de opinião. Solicitou-se aos entrevistados das categorias citadas acima que indicassem nomes de cooperados que apresentassem perfil de liderança; dessa forma, foram escolhidos, entre tais nomes, os 4 citados com maior freqüência.

\section{Resultados}

\section{Análise Ambiental e Postura Estratégica da Cooperativa Alfa}

Quando foi solicitado aos entrevistados que expressassem sua opinião sobre o ambiente em que a cooperativa se insere, eles apontaram, em uma análise externa, as oportunidades e ameaças e, sob o ângulo da análise interna, os pontos fortes e fracos da organização. Dessa forma, foram coletadas as sumariadas a seguir. 


\section{Oportunidades do Ambiente}

- Alfa possui boa localização geográfica, situada na região sul de Minas Gerais, entre as capitais São Paulo, Rio de Janeiro e Belo Horizonte, sendo considerada forte e tradicional bacia leiteira do país.

. Filiada à Cooperativa Central Paulista (São Paulo, SP), possui boa cota que garante mercado cativo para o leite.

. A duplicação da rodovia Fernão Dias (BR-381) abre possibilidades de desenvolvimento do mercado regional.

- Alfa pode explorar mais o mercado regional e de Belo Horizonte com sua marca própria de derivados lácteos.

- Tem planos de intensificar a produção de derivados lácteos com objetivo de diminuir a dependência da Cooperativa Central Paulista, para deixar de ser apenas uma resfriadora de leite e passar a adicionar mais valor ao produto.

- Há possibilidades de diversificação de atividades e incrementar o departamento de café, ainda com movimento modesto para o potencial da região; também pode incentivar a fruticultura entre os cooperados; por exemplo, o figo.

. Fazer parcerias com cooperativas fortes em café da região.

- Vantagem comparativa: a Cooperativa Central Paulista deverá incorporar as marcas fortes das filiadas, comercializando seus produtos em São Paulo.

. Proximidade a universidades e centros de pesquisa e extensão, que difundem novas tecnologias de produção e processamento de produtos, principalmente de leite e café.

\section{Ameaças do Ambiente}

Acirramento da concorrência com multinacionais (Parmalat e Nestlé), que pagam preços diferenciados no leite a seus fornecedores, conforme volume e qualidade.

Alfa tem dificuldades em acompanhar a concorrência comercial com fornecedores de insumos e oferecer preços diferenciados, de acordo com o volume de compra do associado.

. Dependência de mercado com a Cooperativa Central Paulista, atualmente o maior cliente da cooperativa. 
. Risco da Cooperativa Central Paulista falir e faltar mercado para o leite da Alfa.

. Baixa competitividade do sistema cooperativista em relação a seus concorrentes não-cooperativas.

\section{Pontos Fortes da Cooperativa Alfa}

. Boa infra-estrutura física de apoio ao cooperado.

. Tradição, idoneidade e boa imagem na região.

. Boa escala de recepção e processamento de leite: 120 mil litros/dia.

- Oferece boa assistência técnica ao produtor: departamento técnico diversificado composto por veterinários, agrônomos, zootecnistas, entre outros.

. Linha de financiamento para equipamentos e matrizes leiteiras, via cooperativa de crédito própria.

. Oficina mecânica terceirizada.

. Frota terceirizada de tratores (pneus e esteira), a preços competitivos.

. É balizador de preços de produtos e insumos na região.

\section{Pontos Fracos da Cooperativa Alfa}

. Estatuto desatualizado e com perfil paternalista que não diferencia os cooperados fiéis e eficientes daqueles oportunistas e ineficientes.

. Estrutura administrativa muito grande e burocratizada.

- Falta transparência na atual gestão.

. Há poucas reuniões (assembléias) explicativas das ações da diretoria.

. O departamento de café está mal estruturado; muitos associados da Alfa são filiados a outras cooperativas mais fortes em café na região.

. Administração amadora, falta profissionalismo.

- A atual gestão tem priorizado o lado político, esquecendo o lado administrativo de fato.

. A atual gestão não está coesa: seus membros divergem nas decisões.

. Empreguismo, embora em pequena escala, ligado a promessas de campanha. 
. Deve eliminar o supermercado e farmácia, concentrando-se na oferta mais competitiva de insumos destinados à produção.

. O departamento de compras e vendas está atrofiado para o porte da cooperativa.

. Mantém linhas de leite deficitárias por interesses políticos e para cumprir promessas de campanha.

. Mantém, no quadro de cooperados, muitos pequenos produtores ineficientes, por interesses políticos.

- A atual diretoria não está concentrando esforços na fábrica de ração (ociosa) para oferecer preços competitivos e diferenciados aos associados conforme seu volume de compra.

. Alfa não firmou no mercado regional sua marca própria de produtos lácteos, devido ao marketing deficiente.

. Há risco de cisão, pois há um grupo de médios e grandes produtores espalhando o boato de que irão sair da cooperativa e montar uma associação paralela (maioria apoiou a chapa perdedora).

Nota-se que os entrevistados conhecem os problemas administrativos da cooperativa, possuem noção do ambiente empresarial no qual a organização se insere, $\mathrm{e}$ propõem ações no sentido de tornar a cooperativa mais competitiva. Entretanto todos concordam em que a reação da organização ao ambiente tem sido lenta, principalmente devido a que as decisões estratégicas se tomam de forma colegiada, em esporádicas assembléias que, no geral, apresentam baixa participação dos associados.

Não há na cooperativa, segundo os entrevistados, planejamento estratégico com objetivos e metas que sejam seguidos a médio ou longo prazo. Existem, na realidade, propostas das chapas divulgadas na época da eleição, as quais a chefia procura cumprir ao longo do mandato. Essa falta de planejamento estratégico põe em cheque a eficiência da postura estratégica da cooperativa, evidenciando o caráter amador da administração. Se não há objetivos e metas de longo prazo para serem seguidos, há possibilidade de ocorrer descontinuidade nas estratégias, prejudicando tanto sua formulação quanto a implementação, principalmente quando há divergências políticas entre grupos de interesse.

Na opinião de um cooperado da chapa perdedora, o problema da ausência de planos estratégicos é consequiência da própria cultura da cooperativa, na qual o quadro de cooperados, por natureza individualista, se esforça em levar adiante um negócio comunitário, e acrescenta: 
“o pessoal não gosta de reunião, é mais fácil se acomodar e deixar como está [...] São poucas as assembléias na cooperativa [...] além de nos reunirmos pouco, outro problema é o conteúdo discutido nas assembléias: geralmente não passa de mera prestação anual de contas e raramente são discutidos assuntos estratégicos que poderiam trazer vantagem competitiva para a cooperativa. É, geralmente, o momento de exteriorização de frustrações e ressentimentos. Dessa forma, deixa de ser uma coisa construtiva" (Relato de entrevista).

Estatística levantada a partir das assembléias ocorridas na cooperativa, no período de 1990/97, demonstram que nesses oito anos aconteceram as Assembléias Gerais Ordinárias (AGO's) anuais exigidas por lei e apenas 4 Assembléias Gerais Extraordinárias (AGE’s). Além disso, a participação dos associados foi muito baixa; no geral, entre 3 a 16\%, com exceção nas 3 AGO's, cuja pauta do dia era a eleição da diretoria, com participação entre 66 e 75\%. Para uma organização com faturamento anual próximo a 30 milhões de reais, os associados se reúnem muito pouco para discutir os problemas internos da cooperativa e traçar estratégias para o futuro. Tal fato é lamentável, pois o momento mais oportuno para se discutirem os assuntos estratégicos da cooperativa é justamente nas assembléias.

\section{Articulaçóes Políticas na Última Eleiçáo da Diretoria da Cooperativa Alfa}

Na época que precedeu a última eleição focalizada, março de 1996, havia um movimento que visava a compor uma chapa única formada a partir do consenso entre os cooperados. A formação dessa chapa tinha por objetivo fazer uma composição de pessoas consideradas aptas (com interesse na cooperativa, visão estratégica do setor agropecuário, visão sistêmica do cooperativismo e capacidade gerencial), e que tivessem o aval dos cooperados para evitar-se uma provável cisão, que poderia levar à formação de outras chapas, com as inevitáveis disputas políticas. Entretanto isso não aconteceu. Houve divergências na formação da chapa única e a cisão foi inevitável. Assim, foram formadas 2 chapas que disputaram a eleição.

As chapas eram compostas por 12 membros: 3 membros da diretoria executiva, 3 membros do conselho de administração e 6 membros do conselho fiscal. Obedecia-se, assim, às imposições da legislação cooperativista (Lei 5.764/71) e regulamentada pelo estatuto de Alfa.

Iniciou-se a campanha eleitoral com as chapas apresentando suas propostas para a próxima gestão da cooperativa. No processo de divulgação das propostas, cada chapa utilizou táticas distintas, sendo que ambas evitaram o uso do jornal 
interno da cooperativa. A chapa perdedora utilizou, como veículo de divulgação, mala direta endereçada a cada cooperado. A chapa vencedora publicou suas propostas no jornal do município com circulação regional. Mais importante que o veículo de divulgação utilizado, logicamente foi o conteúdo das propostas, as quais buscavam apresentar soluções para os problemas latentes da cooperativa.

O confronto das duas chapas buscava, em síntese, atender a interesses políticos divergentes, reunindo, de um lado, a minoria constituída de médios e grandes produtores; e, de outro, a maioria, formada por pequenos produtores.

As propostas da chapa perdedora, basicamente formada por médios e grandes produtores, buscavam atacar os problemas internos da cooperativa, principalmente enxugar a estrutura administrativa e profissionalizá-la. Também, havia propostas de incentivar a eficiência produtiva dos associados, preconizando maior produtividade e qualidade; e, de certa forma, excluir ou punir os cooperados improdutivos e oportunistas.

A chapa vencedora, basicamente formada por pequenos produtores, divulgou suas propostas com a crença de que os problemas da cooperativa eram externos e havia necessidade de expandir o mercado e adicionar valor ao leite, principal produto da cooperativa, mediante a industrialização. Neste sentido, adotou ações mais populistas, principalmente expandindo a área geográfica de atuação da cooperativa em regiões que buscavam beneficiar pequenos produtores.

Quando foi perguntado aos cooperados que motivos os levaram a formar a chapa para disputar a eleição, as respostas, tanto dos membros da chapa vencedora quanto da perdedora, apontavam sempre, em regra geral, para os problemas da cooperativa e as propostas formais apresentadas pela chapa para solucioná-las.

Entretanto, quando foram solicitadas as opiniões desses cooperados a respeito das estratégias eleitorais da chapa oponente, começaram a aparecer os aspectos informais, envolvidos no processo político, e o jogo de interesses dos grupos. Depoimento de um membro da chapa perdedora ilustra o fato.

"As propostas de nossa chapa visavam descentralizar a administração da cooperativa, procurando dar à diretoria uma conotação mais moderna e profissional; queríamos enxugar a cooperativa, pois alguns setores estavam deficitários; terceirizar serviços, tentar comercializar melhor nossos produtos e atender ao cooperado na medida das possibilidades [...] Era preciso acabar com o sistema paternalista e exigir dos cooperados, principalmente dos pequenos, maior participação, qualidade dos produtos e fidelidade à cooperativa. Pretendíamos dar uma total assistência àqueles produtores com produção inferior a 50 litros de leite/dia, para que eles pudes- 
sem crescer. A idéia era tentar trabalhar com aqueles que queriam, sabiam e não tinham dinheiro para investir. No entanto a chapa oponente começou a espalhar o boato de que queríamos acabar com os pequenos. Isso pegou e foi decisivo para que perdêssemos a eleição" (Relato de entrevista).

Esse boato de "acabar com os pequenos" não foi confirmado claramente pelos membros da chapa vencedora. $\mathrm{O}$ fato aconteceu pelo lado informal da campanha, porém foi possível perceber o uso dessa estratégia, por meio de algumas palavras sutis colocadas oficialmente nas propostas formais da chapa vencedora, divulgadas no jornal do município, cujo texto dizia claramente "para todos os associados" e em seguida "sem distinção". Outro membro da chapa perdedora acrescenta:

"além de espalharem esse boato, eles trabalharam muito em cidades onde predominam pequenos produtores e não existia linha de leite, somente a loja de insumos da cooperativa. Então, prometeram que, se ganhassem a eleição, colocariam nessas cidades a linha de leite e o posto de resfriamento. Isso, em minha opinião, foi decisivo na campanha. Perdemos porque não soubemos fazer política e quem ganha geralmente não são os mais aptos e sim os melhores políticos" (Relato de entrevista).

Outro depoimento, agora de um membro da chapa vencedora, deixou evidenciado que tal boato era verídico.

"Isso muitas vezes é explorado como artifício de campanha política [...] o problema é de visão empresarial. O que se via era que a chapa oponente queria fechar a cooperativa em torno de um grupo e com uma visão mais estreita do negócio, preocupados mais em ficar vigiando vaca, uma visão mais dentro da propriedade [...] Nosso grupo é um pessoal com visão mais empresarial [...] Eu vejo que não é só maximizar a produção da vaca. Precisamos abrir essa cooperativa como um negócio rentável que extrapola a vaca [...] A grande divergência das chapas, na minha opinião, foi a visão empresarial, a outra chapa tinha uma visão muito interna, endógena e exclusivista" (Relato de entrevista).

Para ilustrar como, às vezes, os interesses políticos estão acima dos reais interesses da organização, o depoimento de um membro da chapa vencedora foi surpreendente: "hoje tenho consciência de que montamos nossa chapa mais para ganhar a eleição do que efetivamente para administrar a cooperativa".

Talvez, as pessoas mais atingidas com as periódicas mudanças de gestão na cooperativa sejam os funcionários, que julgaram esse processo eleitoral como incidente crítico na organização. Todos os funcionários entrevistados citaram que 
o clima organizacional na cooperativa, antes da eleição, apresentava características de tensão, expectativa, medo e insegurança. Alguns depoimentos levantados foram: "Não tomamos partido de ninguém [...] Fica um clima político, de mudança, e a gente deve ficar neutro, imparcial [...] Existia a situação e a oposição; então eu me afastava de qualquer 'rodinha' de cooperados, era comprometedor [...] O funcionário sempre tem preferência por uma chapa, mas não comenta com ninguém" (Relatos de entrevista).

Questionou-se também, dos funcionários, como ficou o clima na cooperativa após as eleições. As respostas demonstraram que o clima de tensão, expectativa, medo e insegurança continuava, surgindo outro fator significativo o revanchismo. Alguns depoimentos coletados neste sentido foram:

"A chapa perdedora fica no pé da gente, a fim de achar uma falha para criticar a nova diretoria [...] Temos que nos esforçar ao máximo para não deixar rabo para ninguém pisar [...] A cada diretoria que entra, você tem que mostrar quem você é, comprovar sua competência [...] Não se sabe o que vai acontecer, quais mudanças virão pela frente [...] Há incerteza em relação à nossa função, se ficaremos onde estamos ou se seremos remanejados para outro setor da cooperativa" (Relatos de entrevista).

Ainda, segundo a maioria dos funcionários, após as eleições, de uma forma ou outra, sempre acaba acontecendo alguma mudança na rotina de trabalho dessas pessoas. Há mudanças no estilo de comando, na forma de apresentação dos relatórios, na administração do tempo; cada novo diretor imprime seu estilo pessoal na gerência, que sempre envolve mudanças. Também, há contratações e demissões de funcionários devido à mudança da diretoria, embora em pequena escala. "Quem entra quer trazer gente de sua confiança [...] Isso depende muito das metas da nova diretoria [...] Às vezes há perseguições [...] Quando a nova diretoria é da oposição, aí é que o bicho pega; os novos diretores chegam querendo mudar tudo" (Relatos de entrevista).

Os depoimentos acima demonstram que esse processo eleitoral na Cooperativa Alfa foi palco de disputas políticas entre as duas chapas que utilizaram na campanha táticas formais e informais na disputa pelo poder; contudo imprimiram ao processo uma conotação mais política do que ideológica.

A atual estrutura de poder imposta pela legislação às cooperativas brasileiras tem promovido esse processo cíclico de eleições, fazendo com que aflore periodicamente o jogo de interesses, conflitos e uso da política na disputa pelo poder que, gradativamente, se vão sedimentando como valores na cultura da organização. 


\section{Implicações da Mudança de Gestão nas Estratégias da Cooperativa Alfa}

As cíclicas mudanças de gestão, a cada três anos, conforme prevê o estatuto da Cooperativa Alfa, na opinião da maioria dos entrevistados apresenta aspectos positivos e negativos. De um lado, é benéfica por permitir a renovação de diretores e a geração de novas idéias. Por outro lado, é palco de disputas políticas e provoca clima de revanchismo na chapa perdedora.

Devido à ausência de planejamento estratégico em Alfa, trabalha-se dentro do horizonte de tempo de cada gestão, procurando-se planejar e implementar ações baseadas nas propostas de campanha eleitoral. Muitas vezes, por questões políticas, alguns planos traçados na gestão anterior são abandonados, dando lugar a novas propostas de campanha de chapas de oposição. Alguns depoimentos ilustram o fato.

"Com essas eleições periódicas a cooperativa fica sem uma linha de pensamento. Aqueles que entram armam uma estratégia para trabalharem por três anos; os que entram na gestão seguinte acham que está errado e mudam o rumo das decisões. Isso é problemático e dificulta os planos de longo prazo [...] Pode haver descontinuidade, há muitos descontentes com a atual diretoria e fatalmente haverá mudanças nos planos da próxima gestão. Acredito que os interesses políticos são divergentes [...] Como não existe planejamento estratégico, ninguém vê essa cooperativa daqui a 10 anos. Falta visão estratégica; o amadorismo é grande, administra-se só o operacional; é uma administração do tipo bombeiro, apaga-se o fogo" (Relatos de entrevista).

Devido ao duplo papel que os cooperados assumem de serem ao mesmo tempo donos e usuários das cooperativas, sempre haverá conflitos de interesse no que se refere as estratégias da organização e às estratégias dos cooperados; enquanto empresários individuais, esse problema surge pela própria característica de autogestão das cooperativas brasileiras.

No mesmo sentido, existem problemas administrativos latentes na Cooperativa Alfa que precisam ser resolvidos independentemente da disputa pelo poder entre os cooperados. Os mais evidentes são: falta de planejamento estratégico para ser seguido pelas futuras diretorias; necessidade de profissionalização dos dirigentes; necessidade de sanear a estrutura administrativa (desburocratização e redução do quadro de funcionários); atualização do estatuto com definição de regras claras quanto à admissão e desligamento de cooperados de acordo com seu grau de fidelidade e eficiência. Tais problemas envolvem decisões difíceis e delicadas, 
pois podem ser contrárias aos valores culturais e interesses políticos da maioria dos membros da organização.

\section{Considerações Finals}

A análise dos resultados permite fazer algumas reflexões sobre a influência da mudança de gestão nas estratégias da Cooperativa Alfa.

- A última eleição de diretoria estudada pode ser considerada como um incidente crítico para a organização, pois envolveu disputas políticas entre as chapas, provocando reflexos traumáticos em todos os envolvidos no processo (membros da chapa vencedora e perdedora, funcionários e cooperados).

. Há consciência, entre os entrevistados, de que a cooperativa está exposta a várias influências ambientais, tanto externas (ameaças e oportunidades) quanto internas (pontos fracos e fortes); a resposta da organização ao ambiente tem sido lenta, principalmente porque as decisões estratégicas são tomadas de forma colegiada, em esporádicas assembléias que, no geral, apresentam baixa participação dos associados.

. Não há planejamento estratégico na cooperativa; as estratégias limitam-se às propostas de campanha divulgadas pelas chapas na época da eleição, procurando-se cumpri-las durante o período de mandato. Tal fato pode influenciar as estratégias tanto no nível de sua formulação quanto naquele de sua implementação e provocar sua descontinuidade a médio e longo prazo, principalmente se as diretrizes forem divergentes com referência aos interesses políticos da diretoria sucessora.

- Os principais fatores ligados à mudança de gestão que podem influenciar as estratégias da cooperativa são: ausência de planejamento estratégico, amadorismo gerencial da diretoria e divergências políticas dos grupos de interesse (situação e oposição) envolvidos na disputa pelo poder.

As cíclicas mudanças de gestão, na opinião dos entrevistados, podem exercer influências positivas na postura estratégica da cooperativa (permitem a renovação de diretores, motivam a geração de novas idéias, evitam a perpetuação de grupos no poder, entre outras); por outro lado, apresentam influências negativas (são palco de disputas políticas, provocam clima de revanchismo na chapa perdedora, podem ocorrer descontinuidade nas estratégias, entre outras).

. Os funcionários foram afetados pela última mudança de gestão focalizada; se- 
gundo eles, o clima organizacional, antes e depois das eleições, apresentou características de tensão, expectativa, medo e insegurança. Houve mudanças na rotina de trabalho dessas pessoas, principalmente após a eleição, quando os novos diretores imprimiram seu estilo pessoal na gerência da cooperativa.

- A profissionalização, na opinião de todos entrevistados, é boa saída para resolver os problemas administrativos da cooperativa, havendo a intenção de contratar profissionais para ocupar cargos de média gerência. Entretanto a profissionalização dos cargos de diretoria ainda é assunto pouco discutido. Tal fato reflete, em parte, a característica cultural da cooperativa, na qual o tradicionalismo e interesses políticos entram em conflito com a necessidade da organização de conquistar a eficácia administrativa e competitividade empresarial.

- Com a globalização e o acirramento da competitividade, as organizações devem direcionar suas estratégias no sentido de responder rapidamente às demandas ambientais. De certa forma, a última mudança de gestão ocorrida na cooperativa estudada agiu em sentido contrário, porquanto gerou um clima de expectativa e conflito interno que retardou suas ações estratégicas.

\section{ReferênCIAS Bibliográficas}

ACI.

XXX Congress Tokyo : agenda and raports. Review of International Cooperation, $v$. 85, n. 2-3, Abr./Jul. 1992.

ACKOFF, R. L.

Planejamento empresarial. São Paulo : Livros Técnicos e Científicos, 1976.

ALENCAR, E.

Valorização da cooperativa agrícola de Curvelo-MG. Viçosa, 1976. Dissertação (Mestrado em Extensão Rural) - Universidade Federal de Viçosa.
ANSOFF, H. I.

Estratégia empresarial. São Paulo : McGraw-Hill, 1977.

A nova estratégia empresarial. São Paulo : Atlas, 1990.

\section{BALDE BRANCO.}

Cooperativismo : dirigentes discutem o futuro do setor e a própria capacitação. p. 45-77, jul. 1997.

BERNARDO, E. E. R.

A crise no cooperativismo. In: XX ENCONTRO ANUAL DA ANPAD (1996: Angra dos Reis). Anais... Rio de Janeiro : ANPAD, 1996. p. 125-139. 
BURSZTYN, P. R.

O poder dos donos. Petrópolis : Vozes, 1985.

CARBONELL DE MASY, R. Análise crítica da legislação cooperativa no Brasil. Perspectiva Econômica, v. 8, n.17, 1978. Série Cooperativismo. v. 1.

Moderna gestión de empresas cooperativas agrarias. Valencia : Conselléria de Trabajo del País Valenciano, 1980.

CÁRIO, S. A. F.

Estudo sobre o controle e a participação numa cooperativa de $2^{\circ}$ grau em Santa Catarina. Perspectiva Econômica, v. 19, n. 51, p. 109-127, 1985. Série Cooperativismo. v. 16.

CÉSAR, J.

Valorização da administração e da cooperativa no subsistema rural : um estudo de caso. Lavras, 1977. Dissertação (Mestrado em Administração Rural) - Departamento de Administração e Economia, Universidade Federal de Lavras.

\section{CHOMEL, A.}

La réorganisation de l'alliance : le débat sur les valeurs, l'aide aux coopératives d'Europe Orientale. Revue des Études Coopératives Mutualistes et Associatives, $n$. 44-45, Oct. 1992.
FISCHER, R. M.

O círculo do poder : as práticas invisíveis de sujeição nas organizações complexas. In: FLEURY, M. T. L.; FISCHER, R. M. (Coords.). Cultura e poder nas organizações. São Paulo : Atlas, 1989. p. 65-87.

FISCHMANN, A. A.

Implementação de estratégias : identificação e análise de problemas. São Paulo, 1987. Tese (Livre-Docência) - Faculdade de Economia, Administração e Contabilidade, Universidade de São Paulo.

FISCHMANN, A. A.;

ALMEIDA, M. I. R.

Planejamento estratégico na prática. São Paulo : Atlas, 1991.

FLEURY, M. T. L.

Cooperativas agrícolas e o capitalismo no Brasil. São Paulo : Global Editora, 1983.

O desvendar a cultura de uma organização : uma discussão metodológica. In: FLEURY, M. T. L.; FISCHER, R. M. (Coords.) Cultura e poder nas organizações. São Paulo : Atlas, 1989. p. 15-27.

FOUCAULT, M.

Microfísica do poder. Rio de Janeiro : Edições Graal, 1993. 
GALBRAITH, J. K.

Anatomia do poder. São Paulo : Pioneira, 1989.

GARCIA, R. M.

$O$ requisito de um programa de treinamento em cooperativas. Revista de Administração de Empresas, v. 21, n.1, p. 39-45, jan./mar. 1981.

GODOY, A. S.

Introdução à pesquisa qualitativa e suas possibilidades. Revista de Administração de Empresas, v. 35, n. 3, maio/jun. 1995.

GRAMACHO, A.

Cooperativas agrícolas e globalização. Agroanalysis, p. 14-15, ago. 1997.

HERMIDA, J.;

SERRA, R.;

KASTIKA, E.

Administración y estrategia : teória y práctica. Buenos Aires : Ediciones Macchi, 1992.

JANK, M. S.

Agenda do dia para as cooperativas : no setor agropecuário, entidades têm de lidar com concorrência acirrada e precisam rever suas regras. Folha de São Paulo, 18 jun. 1997. Caderno de Economia.
LAUSCHNER, R.;

SCHWEINBERGER, G. A.

Eficiencia y eficacia de la empresa cooperativa y estructura de poder. Perspectiva Econômica, v. 24, n. 65, p. 11-26, abr./maio 1989.

MAURER JÚNIOR, T. H.

O cooperativismo : um ideal de solidariedade humana na vida econômica. São Paulo : SNT, 1970.

MAXIMINIANO, A. C. A.

Teoria geral da administração : da escola científica à competitividade em economia globalizada. São Paulo : Atlas, 1997.

MEIRELES, P. A.

Ações administrativas e participação social em cooperativas agropecuárias. Lavras, 1981. Dissertação (Mestrado em Administração Rural) - Departamento de Administração e Economia, Universidade Federal de Lavras.

MORAES, C. L. DE.

Participação do cooperado na cooperativa : uma abordagem contingencial do desenvolvimento e crescimento da cooperativa mista e do cooperado. Perspectiva Econômica, v. 29, n. 84, p. 125-143, 1994. Série Cooperativismo. v. 35.

MORGAN, G.

Imagens da organização. São Paulo : Atlas, 1996. 
OLIVEIRA, B. A. M. DE.

Coprocol : um caso de contrapoder cooperativo? Lavras, 1996. Dissertação (Mestrado em Administração Rural) - Departamento de Administração e Economia, Universidade Federal de Lavras.

OLIVEIRA, D. P. R.

Planejamento estratégico : conceitos, metodologias e práticas. São Paulo : Atlas, 1989.

OLIVEIRA, N. B.

Cooperativismo : guia prático. Porto Alegre : OCERGS, 1984.

PAGÈS, M.

O poder das organizações : a dominação das multinacionais sobre os indivíduos. São Paulo : Atlas, 1987.

PEREIRA, V. DA G.;

BRITO, M. J. DE.

A organização como um sistema político : um estudo do poder entre os membros da diretoria de uma cooperativa agrícola. In: XVIII ENCONTRO ANUAL DA ANPAD (1994 : Curitiba). Anais... Curitiba: ANPAD, 1994. v. 4. p.168-176.

PINHO, C. M.

Manual de cooperativismo. São Paulo : Coopercultura/CNPq, 1981.
PINHO, D. B.

A doutrina cooperativa nos regimes capitalista e socialista. São Paulo : Pioneira, 1966.

Manual de cooperativismo. São Paulo : Coopercultura/CNPq, 1981. v. 2.

RODRIGUES, R.

O cooperativismo na globalização. Agroanalysis, p. 10-12, ago. 1997.

SCHEIN, E. H.

Organizational culture and leadership : a dynamic review. London : Jossey- Bass, 1985.

SCHULZE, E.

Estrutura do poder em cooperativas. Perspectiva Econômica, v. 22, n. 59, p. 49-76, jun./dez. 1987. Série Cooperativismo. v. 22.

SILVA, T. N. DA.

Participação dos cooperados na gestão de cooperativas de produção : uma análise da separação entre propriedade e controle. Perspectiva Econômica, v. 29 , n. 86 , p. 05-97, 1994. Série Cooperativismo. v. 36.

SORJ, B.

Estado e classes sociais na agricultura brasileira. Rio de Janeiro : Zahar, 1980. 
TRIVIÑOS, A. N. S.

Introdução à pesquisa em ciências sociais. São Paulo: Atlas, 1992.

YIN, R. K.

Case study research : design and methods. London : Sage Publications, 1989.
ZALESNIK, A.;

VRIES, M. F. R.

$O$ poder e a mente empresarial. São Paulo : Enio Atheus Guazzelli \& Cia, 1981.

ZYLBERSZTAJN, D.

Organização de cooperativas : desafios e tendências. Revista de Administração, v. 29, n. 3, p. 23-32, jul./set. 1994. 